\title{
APLIKASI SISTEM PAKAR PENGOPERASIAN DAN TROUBLESHOOTING PADA MESIN HEIDELBERG GTO V 52
}

\author{
Dr. Pahlawan Sagala, Muluk Dharmayana \\ Program Studi Sistem Informasi \\ STMIK Indonesia Mandiri, Jl.Jakarta No.79 Bandung \\ Email:psagala@gmail.com
}

\begin{abstract}
ABSTRAK
Industri percetakan dengan nilai aset yang sangat tinggi dan biaya perawatan yang tidak sedikit membutuhkan tenaga ahli yang menguasai teknik cetak serta perawatan mesin yang memadai. Kurangnya pendidikan dan pelatihan di bidang percetakan, khususnya dalam teknik cetak grafika menjadi salah satu masalah bagi karyawan untuk mengoperasikan dan menyelesaikan permasalahan mesin cetak pada teknik cetak grafika.

Penelitian ini memberikan solusi sistem pembelajaran dengan menggunakan sistem pakar yang bertujuan untuk memecahkan masalah penggunaan mesin cetak offset Heidelberg bagi operator. Software yang dibangun dengan basis website menyajikan solusi yang tepat, akurat, efesien dan menunjukan langkah-langkah operasionalnya sehingga dapat mempermudah operator dan menghemat waktu perbaikan.
\end{abstract}

Kata Kunci : mesin cetak offset, sistem pakar, mesin Heidelberg, sistem pakar cetak offset

\section{LATAR BELAKANG}

PT. GRANESIA adalah suatu badan usaha bisnis, yang bergerak dalam bidang jasa Percetakan dan Penerbitan yang berlokasi di kota Bandung. Sebagai suatu badan usaha bisnis, dalam industri percetakan dengan nilai aset yang sangat tinggi dan biaya perawatan yang tidak sedikit membutuhkan tenaga ahli yang menguasai teknik cetak serta perawatan mesin di perusahaan percetakan. Salah satu mesin cetak offset yang digunakan adalah mesin Heidelberg GTO V 52 yang masih menggunakan pengoperasian secara manual. Dengan berkembangnya teknologi di bidang percetakan, mesin-mesin cetak offset tentu mengalami perubahan pengoperasian dari manual ke digital. Hal ini menjadi permasalahan bagi perusahaan berkembang yang hanya mempunyai mesin dengan sistem manual karena perbandingan kapasitas mesin digital / automatic jauh lebih baik, kecepatan hasil produksi jauh lebih cepat serta perawatan yang sedikit.

Operator atau teknisi senior yang memiliki pemahaman dan pengalaman dalam menangani mesin manual sangat diperlukan, akan tetapi belakangan ini makin sedikit jumlahnya karena masuk usia pension atau mengundurkan diri. Antisipasi 
terhadap berkurang tenaga yang berpengalaman adalah dengan memberi pelatihan kepada tenaga kerja baru oleh sampai mencapai tingkat yang dipersyaratkan oleh perusahaan. Umumnya pelatihan tenaga kerja baru untuk bisa jadi operator mesin memerlukan waktu lama dan biaya besar. Untuk meminimalisir biaya pelatihan bagi tenaga operator junior agar mampu secara cepat menangani kesalahan ataupun troubleshooting pada saat proses cetak maka operator perlu diperlengkapi dengan software bertidak sebagai pakar tempat bertanya.

Software yang di maksud adalah suatu perangkat lunak sistem pakar yang bersumber dari seorang ahli dalam bidang diagnosis dan analisis cara penanganan mesin cetak offset Heidelberg tersebut. Dengan dibangunnya Sistem pakar pengoperasian dan troubleshooting pada Mesin Cetak Offset Heidelberg GTO V 52 di harapkan dapat memberikan kebebasan akses dalam membantu pengguna komputer dalam menangani masalah. Berdasarkan permasalahan diatas, maka perlu dirancang suatu sistem yang dapat memberikan solusi yang akurat, sehingga dapat menekan waktu dan biaya untuk mengatasi masalah - masalah kerusakan pada mesin cetak Offset Heidelberg tersebut. Untuk itu perlu dibuat suatu sistem yang akan dijadikan materi tulisan dengan judul "APLIKASI SISTEM PAKAR PENGOPERASIAN DAN TROUBLESHOOTING PADA MESIN CETAK OFFSET HEIDELBERG GTO V 52 BERBASIS WEB”.

\section{LANDASAN TEORI}

\subsection{Teknik Grafika}

Dalam teknik cetak grafika telah dikenal sebutan dengan nama teknik cetak tinggi dan teknik cetak dalam. Untuk lebih jelasnya, dibawah ini diperlihatkan skema teknologi teknik cetak grafika yang umum di industri percetakan. 


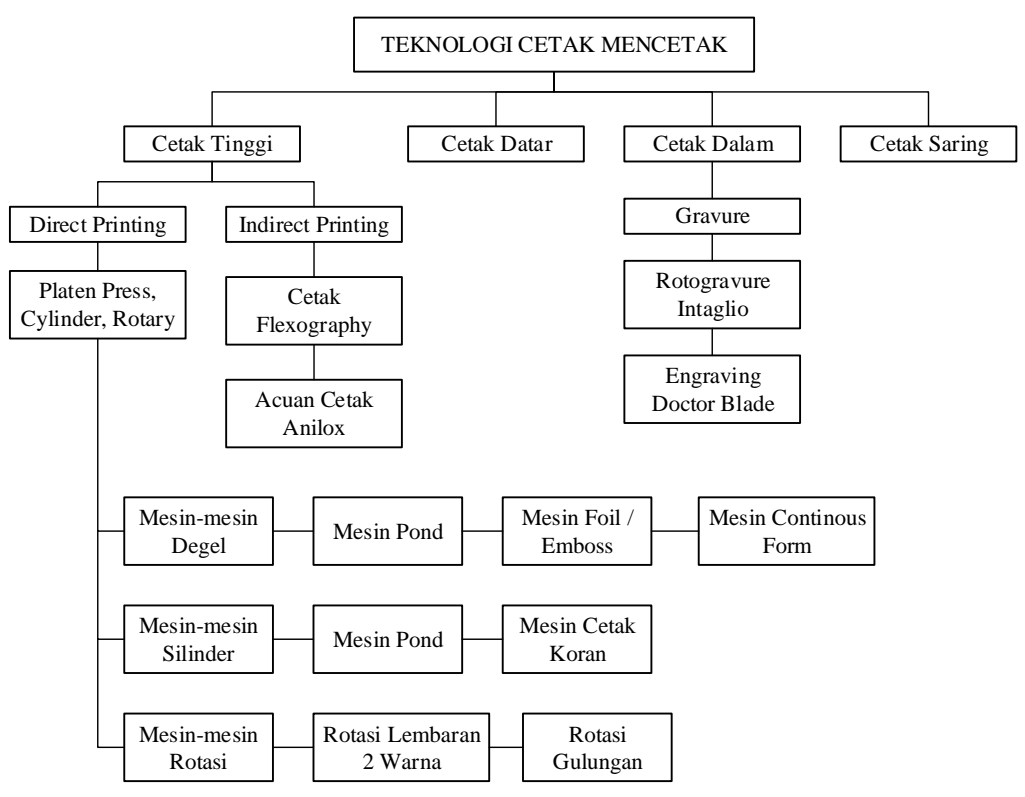

GAMBAR 1.1. Skema Teknologi Cetak Mencetak

Pada kasus dalam penelitian ini yang akan dibahas adalah mengenai teknik cetak tinggi. Disebut cetak tinggi karena pada acuan cetaknya permukaan bagian yang mencetak lebih tinggi dari pada bagian yang tidak mencetak. Cetak tinggi ada dua macam, yaitu cetak letterpress dan cetak flekso. Hal yang membedakan antara letterpress dan cetak flekso adalah acuan cetaknya. Acuan cetak letterpress terbuat dari bahan yang keras, sedangkan acuan cetak flekso terbuat dari bahan yang elastic atau fleksibel.

\subsubsection{Mesin Cetak Heidelberg GTO V 52}

Salah satu jenis mesin cetak Teknik cetak tingg untuk cetak lembaran adalah merk Heidelberg tipe GTO V 52. Berdasarkan hasil pengumpulan data, mesin GTO V ini terdiri dari 3 bagian utama, yaitu Feeder unit, Press Unit dan Delivery Unit. Untuk tiap bagian mempunyai fungsi masing-masing tetapi tidak dapat dipisahkan satu sama lainnya. 


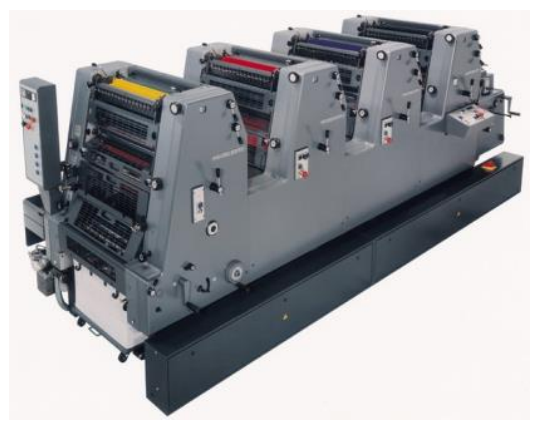

GAMBAR 1.2. Heidelberg GTO V 52 4P

Feeder adalah bagian dari mesin cetak offset yang biasa disebut dengan unit masukan kertas. Pengaturan dan penyetelan bagian feeder dilakukan untuk menyesuaikan masukan kertas sesuai dengan jenis kertasnya. Pada unit Feeder ini terdapat angin, sucker house, gripper dan penyetelan batas kertas. Setiap bagian tersebut mempunyai dampak yang sangat beresiko terhadap proses input kertas, maka dari itu perlu dilakukan penyesuaian dan pengaturan agar masuknya kertas ke mesin offset pada saat mencetak menjadi baik dan lancar.

Setelah unit feeder diatur dengan baik selanjutnya kertas akan masuk ke bagian Press (cetak). Unit ini merupakan bagian utama dari proses cetak karena pengaturan warna dan register harus sesuai berdasarkan standard yang ditetapkan.

Terakhir pada bagian delivery unit adalah unit yang digunakan sebagai output pada proses mencetak. Unit ini dapat mengatur cara keluarnya kertas sesuai dengan gramatur kertas yang digunakan. Untuk itu pengatur angin penghisap, pengaturan angin penghebus, timing paper drop, pengaturan anti set-off powder menjadi bagian yang tidak kalah penting pada proses mencetak.

\subsection{Sistem Pakar}

Sistem pakar menurut Durkin (Sri Kusumadewi 2003 : 108) adalah suatu program komputer yang dirancang untuk memodelkan kemampuan penyelesaian masalah yang dilakukan oleh seorang pakar.

Secara umum, sistem pakar (Expert System) adalah sistem yang berusaha mengadopsi pengetahuan manusia ke komputer, agar komputer dapat menyelesaikan masalah seperti yang biasa dilakukan oleh para ahli. 


\subsubsection{Struktur Sistem Pakar}

Sistem pakar dapat ditampilkan dengan dua lingkungan, yaitu lingkungan pengembangan (development environtment) dan lingkungan konsultasi (consultation environtment). Lingkungan pengembangan digunakan oleh sistem pakar (ES) builder untuk membangun komponen dan memasukkan pengetahuan ke dalam basis pengetahuan. Lingkungan konsultasi digunakan oleh nonpakar untuk memperoleh pengetahuan dan nasihat pakar. Lingkungan ini dapat dipisahkan setelah sistem lengkap. Bentuk Struktur sistem pakar dapat dilihat pada Gambar 2.1 berikut ini.

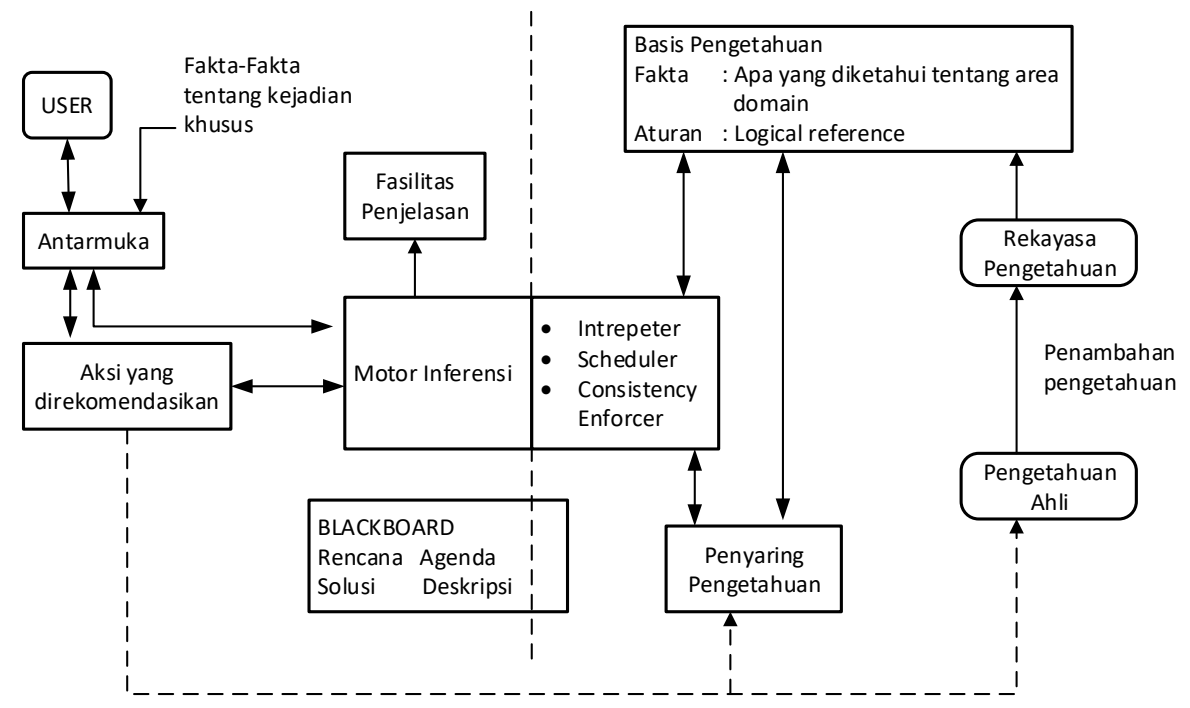

GAMBAR 2.1 Struktur Sistem Pakar (Sri Kusumdewi, 2003)

Komponen-komponen yang ada pada sistem pakar adalah :

Pakar, akuisisi pengetahuan, mesin inferensi (inference engine), workplace, antarmuka Pemakai (User Interface), knowledge engineer, basis pengetahuan, perbaikan pengetahuan, fasilitas penjelasan, aksi yang direkomendasikan, dan user.

\subsubsection{Representasi Pengetahuan}

Pengetahuan merupakan kemampuan untuk membentuk model mental yang menggambarkan objek dengan tepat dan merepresentasikannya dalam aksi yang dilakukan terhadap suatu objek.

Representasi pengetahuan merupakan metode yang digunakan untuk pengkodean pengetahuan dalam sebuah sistem pakar yang berbasis pengetahuan. Perepresentasian 
dimaksudkan untuk menangkap sifat-sifat penting problema dan membuat informasi itu dapat diakses oleh prosedur pemecahan problema.

\section{Tabel Keputusan}

Pengetahuan relasi dapat pula direpresentasikan dalam tabel keputusan. Dalam tabel keputusan, pengetahuan disusun dalam format spreadsheet menggunakan kolom dan baris.

Pengetahuan untuk tabel dikumpulkan dalam sesi akuisisi pengetahuan. Setelah terbentuk, pengetahuan dalam tabel dapat digunakan sebagai input untuk metode representasi pengetahuan yang lain.

\section{Pohon Keputusan}

Pohon keputusan dihubungkan ke tabel dan populer dibanyak tempat. Pohon ini terdiri dari node yang menyatakan tujuan dan link yang menyatakan keputusan.

\subsubsection{Mesin Inferensi (Inference Engine)}

Terdapat dua pendekatan untuk mengontrol inferensi dalam sistem pakar berbasis aturan, yaitu pelacakan ke belakang (backward chaining) dan pelacakan ke depan (forward chaining).

Forward chaining berarti menggunakan aturan kondisi-aksi. Dalam metode ini, data digunakan untuk menentukan aturan mana yang akan dijalankan, kemudian aturan tersebut dijalankan. Metode inferensi forward chaining cocok digunakan untuk menangani masalah pengendalian dan peramalan. Dalam pendekatan ini pelacakan dimulai dari informasi masukan, dan selanjutnya mencoba menggambarkan kesimpulan. Pelacakan ke depan mencari fakta yang sesuai dengan IF dari aturan IF-THEN. Proses forward chaining disajikan pada Gambar 2.2.

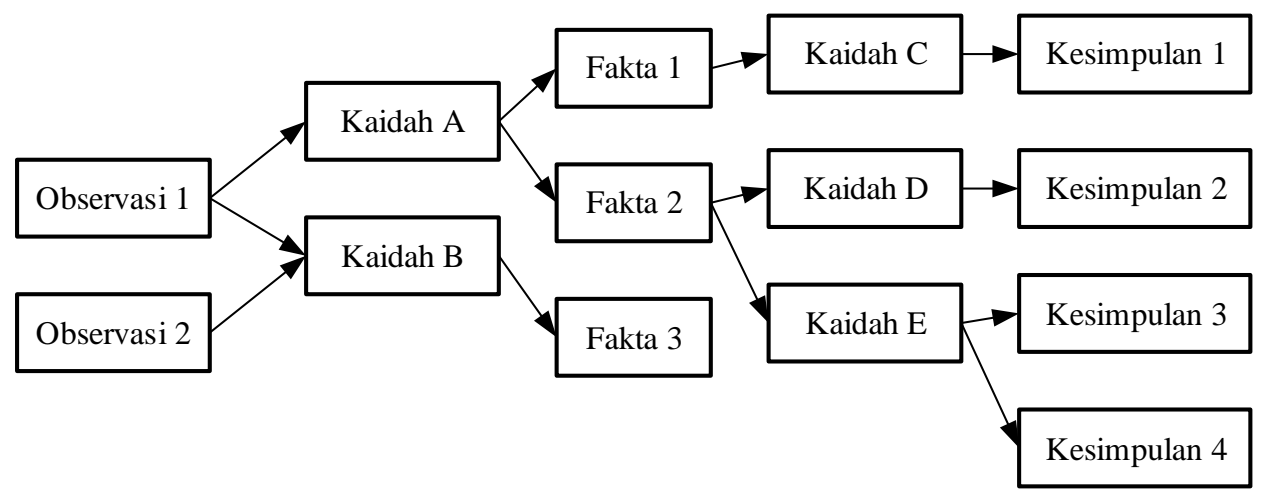

GAMBAR 2.2. Proses Forward Chaining (Arhami, 2005) 


\section{PERANCANGAN DAN HASIL}

\subsection{Analisis Sistem}

Dalam mengembangkan sistem pakar diperlukan pengetahuan dan informasi yang diperoleh dari beberapa sumber, yaitu dari para pakar, melakukan pengamatan langsung serta beberapa buku tentang mesin cetak offset. Analisa sistem pakar bertujuan untuk mengidentifikasi permasalahan yang ada. Analisis ini diperlukan sebagai dasar dalam tahapan perancangan sistem.

\subsubsection{Analisis Pengumpulan Data}

Pengumpulan data dilakukan dengan cara wawancara kepada para pakar dan pengamatan langsung pada saat proses mencetak. Proses pengerjaan pencetakan dari titik awal mesin dinyalakan, pada bagian feeder, sampai pada proses keluarnya hasil cetak pada bagian delivery unit diamati dan dicatat. Data masalah yang sering terjadi pada saat pencetakan dan solusi apa yang harus dilakukan dapat dilihat pada tabel 3.1 dan tabel 3.2 di bawah ini.

TABEL 3.1. Data Masalah (Troubleshooting).

\begin{tabular}{|l|l|}
\hline No & \multicolumn{1}{c|}{ Keterangan } \\
\hline 1 & Mesin tidak bisa dijalankan setelah mesin dihidupkan (power switch on). \\
\hline 2 & Kertas tak terhisap oleh sucker house. \\
\hline 3 & Kertas terhisap rangkap dan mesin berhenti / OFF \\
\hline 4 & Kertas masuk ke stopper jalannya miring dan menyebabkan mesin berhenti / OFF \\
\hline 5 & Hasil cetak berbayang. \\
\hline 6 & Terjadi oversheet pada cetakan. \\
\hline 7 & Terjadi penadaan pada hasil cetak, hasil cetak terlihat tidak rata \\
\hline 8 & Hasil cetak basah. \\
\hline 9 & Terjadi kotor pada pinggiran kertas hasil cetakan dan terjadi berulng kali \\
\hline 10 & Serat kertas tercabut. \\
\hline 11 & Terjadi oksidasi pada hasil cetakan \\
\hline 12 & Terjadi bintik-bintik pada hasil cetakan \\
\hline 13 & Hasil cetak lengket \\
\hline 14 & Keluarnya kertas hasil cetak tidak rapi. \\
\hline 15 & Keluarnya kertas tidak turun ke meja delivery dan mesin berhenti / OFF. \\
\hline
\end{tabular}


TABEL 3.2. Data Solusi

\begin{tabular}{|l|l|}
\hline No & \multicolumn{1}{c|}{ Keterangan } \\
\hline 1 & $\begin{array}{l}\text { Melakukan penyetalan kembali pada unit feeder di bagian stopper, sucker house, } \\
\text { anslaag, dan meja staper. }\end{array}$ \\
\hline 2 & Melakukan register ulang. \\
\hline 3 & Membersihkan atau mencuci blanket dengan cairan pencuci (RWA). \\
\hline 4 & Melakukan pengecekan pada unit pembasah. \\
\hline 5 & Melakukan pengecekan PH kadar air. \\
\hline 6 & Melakukan penyetelan pada rem delivery. \\
\hline 7 & Mengecek ketersediaan serbuk anti setoff. \\
\hline
\end{tabular}

\subsection{Perancangan Sistem Pakar}

Pada pengumpulan data sebelumnya telah dilampirkan tabel permasalahan troubleshooting, akan tetapi dalam perancangan aplikasi sistem pakar harus memperhatikan beberapa faktor antara lain basis pengetahuan, tabel keputusan, pohon keputusan dan perancangan data.

\subsubsection{Basis Pengetahuan}

Basis pengetahuan berisi pengetahuan-pengetahuan dalam penyelesaian masalah, tentu saja di dalam domain tertentu dan merupakan komponen utama dalam membangun sistem pakar. Dalam perancangan sistem pakar ini digunakan bentuk pendekatan basis pengetahuan yang sangat umum digunakan yaitu penalaran berbasis kasus.

TABEL 3.3. Basis Pengetahuan

\begin{tabular}{|c|c|c|}
\hline No. & Kondisi & Keterangan dan Solusi \\
\hline 1. & $\begin{array}{l}\text { Mesin tidak bisa } \\
\text { dijalankan setelah } \\
\text { mesin dihidupkan } \\
\text { (power switch on). }\end{array}$ & $\begin{array}{l}\text { Keterangan : } \\
\text { - Switch Inch terbuka } \\
\text { - Switch motor utama belum dinyalakan } \\
\text { Solusi : } \\
\text { - Periksa dan tutup Switch inch yang ada pada } \\
\text { mesin. } \\
\text { - Periksa dan tekan tombol on pada swith motor } \\
\quad \text { utama pada mesin di bagian belakang. }\end{array}$ \\
\hline 2. & $\begin{array}{l}\text { Lampu } \\
\text { mesin } \\
\text { merah }\end{array}$ & $\begin{array}{l}\text { Keterangan: } \\
\text { • Switch emergency button terbuka. } \\
\text { Solusi : } \\
\text { - Periksa dan tutup switch emergency button pada } \\
\quad \text { mesin }\end{array}$ \\
\hline 3. & \begin{tabular}{ll} 
Lampu & \multicolumn{2}{l}{ indikator } \\
berwarna & biru di
\end{tabular} & $\begin{array}{l}\text { Keterangan : } \\
\text { - Kap pada salah satu atau semua unit terbuka. }\end{array}$ \\
\hline
\end{tabular}




\begin{tabular}{|c|c|c|}
\hline & $\begin{array}{l}\text { semua atau salah } \\
\text { satu unit berkedip. }\end{array}$ & $\begin{array}{l}\text { Solusi : } \\
\quad \text { • Periksa dan tutup kap pada mesin }\end{array}$ \\
\hline 4. & $\begin{array}{l}\text { Kertas tak terhisap } \\
\text { oleh sucker house }\end{array}$ & $\begin{array}{l}\text { Keterangan : } \\
\text { - Angin penghembus kecil / kurang } \\
\text { - Angin hisap kurang/ kecil } \\
\text { - Meja pemasukan terlalu rendah ( Stapel tester ) } \\
\text { - Kertas lengket, kurang kocok } \\
\text { Solusi : } \\
\text { - Tambahkan angin penghembus } \\
\text { - Tambahkan angin penghisap } \\
\text { - Atur dan sesuaikan ketinggian meja pemasukan } \\
\text { - Kocok kertas }\end{array}$ \\
\hline 5. & $\begin{array}{ll}\text { Kertas } & \text { terhisap } \\
\text { rangkap } & \end{array}$ & $\begin{array}{l}\text { Keterangan : } \\
\text { - Angin hembus terlalu besar } \\
\text { - Angin hisap terlalu besar } \\
\text { - Meja pemasukan terlalu tinggi ( Stapel tester) } \\
\text { - Kertas lengket, kurang kocok } \\
\text { Solusi : } \\
\text { - Kurangi angin penghembus. } \\
\text { - Kurangi angin penghisap. } \\
\text { - Atur dan sesuaikan ketinggian meja pemasukan } \\
\text { - Kocok kertas }\end{array}$ \\
\hline 6. & $\begin{array}{l}\text { Kertas jalannya } \\
\text { miring }\end{array}$ & $\begin{array}{l}\text { Keteranagan : } \\
\text { - Roda trasport berat sebelah } \\
\text { - Roda penghantar berat sebelah } \\
\text { Solusi : } \\
\text { - Sejajarkan roda transport } \\
\text { - Atur roda penghantar menjadi seimbang }\end{array}$ \\
\hline 7. & Cetakan lari & $\begin{array}{l}\text { Keterangan : } \\
\text { - Tumpukan kertas pada meja penumpuk kertas } \\
\text { tidak rata } \\
\text { - Bilah penahan kertas pada meja pemasukan terlalu } \\
\text { rapat. } \\
\text { Solusi : } \\
\text { - Ambil kertas pada meja dan tumpuk ulang dengan } \\
\text { dirapikan. } \\
\text { - Potong kembali kertas sekitar } 2 \mathrm{~mm} \text { tanpa } \\
\text { mengurangi ukuran jadi. } \\
\text { - Beri ruang pada pinggiran kertas. }\end{array}$ \\
\hline 8. & $\begin{array}{l}\text { Oversheet } \\
\text { cetakan }\end{array}$ & $\begin{array}{l}\text { Keterangan : } \\
\qquad \text { Tinta lambat kering. } \\
\text { Solusi : } \\
\bullet \quad \text { Berikan pengering pada tinta. }\end{array}$ \\
\hline 9. & $\begin{array}{l}\text { Kotor pada } \\
\text { pinggiran kertas }\end{array}$ & $\begin{array}{l}\text { Keterangan : } \\
\text { - Sisa air pembasah mempengaruhi sifat tinta } \\
\text { - } \text { Air terlalu banyak bercampur dengan tinta } \\
\end{array}$ \\
\hline
\end{tabular}




\begin{tabular}{|c|c|c|}
\hline & & $\begin{array}{l}\text { Solusi : } \\
\text { • Kurangi level air. }\end{array}$ \\
\hline 10. & $\begin{array}{l}\text { Hasil cetakan kabur } \\
\text { ( suram ) dan tidak } \\
\text { merata }\end{array}$ & $\begin{array}{l}\text { Keterangan : } \\
\text { - PH air pembasah tidak tepat. } \\
\text { - Air terlalu banyak pada pelat. } \\
\text { - Kain karet (blanket) mengkilap / mengaca. } \\
\text { Solusi : } \\
\text { - Ukur PH air dengan nilai rekomendasi } 5.5 \\
\text { - Kurangi level air } \\
\text { - Cuci Blanket }\end{array}$ \\
\hline 11. & Serat kertas tercabut & $\begin{array}{l}\text { Keterangan : } \\
\qquad \quad \text { Air terlalu banyak pada pelat } \\
\text { Solusi : } \\
\bullet \quad \text { Kurangi level air }\end{array}$ \\
\hline 12. & $\begin{array}{l}\text { Oksidasi pada kertas } \\
\text { hasil cetak. }\end{array}$ & $\begin{array}{l}\text { Keterangan : } \\
\text { - Pelat terlalu lama kering tanpa } G U M \text { atau } G U M \\
\text { tidak rata } \\
\text { Solusi : } \\
\text { - Ganti plate }\end{array}$ \\
\hline 13. & $\begin{array}{lr}\text { Serat } & \text { kertas } \\
\text { menempel pada tinta }\end{array}$ & $\begin{array}{l}\text { Keterangan : } \\
\text { • Air terlalu banyak pada pelat } \\
\text { Solusi : } \\
\bullet \quad \text { Kurangi level air }\end{array}$ \\
\hline 14. & $\begin{array}{l}\text { Bintik-bintik pada } \\
\text { plate }\end{array}$ & $\begin{array}{l}\text { Keterangan : } \\
\text { - Air terlalu banyak pada pelat } \\
\text { - Terlalu banyak pengering } \\
\text { - Rol hantar tinta / air terlalu kuat ke plate } \\
\text { - Kesalahan pembuatan pelat } \\
\text { Solusi : } \\
\text { - Kurangi level air } \\
\text { - Kurangi anti setoff powder } \\
\text { - Atur ulang rol hantar. } \\
\text { - Ganti plat. }\end{array}$ \\
\hline 15 & Plate cepat rontok & $\begin{array}{l}\text { Keterangan : } \\
\text { - Rol hantar tinta / air terlalu kuat ke plate. } \\
\text { - Kesalahan pembuatan pelat } \\
\text { Solusi : } \\
\text { - Atur ulang rol hantar. } \\
\text { - Ganti plat. }\end{array}$ \\
\hline 16. & $\begin{array}{l}\text { Bintik-Bintik pada } \\
\text { gambar }\end{array}$ & $\begin{array}{l}\text { Keterangan : } \\
\bullet \quad \text { Tinta lambat kering } \\
\text { Solusi : } \\
\bullet \quad \text { Tambahkan pengering dan berikan angin. }\end{array}$ \\
\hline 17. & $\begin{array}{l}\text { Hasil cetak } \\
\text { berbayang } \\
(\text { doubleren })\end{array}$ & $\begin{array}{l}\text { Keterangan: } \\
\text { - Setelah merubah plat, kain karet (blanket) tidak di } \\
\text { cuci }\end{array}$ \\
\hline
\end{tabular}




\begin{tabular}{|c|c|c|}
\hline & & $\begin{array}{l}\text { Solusi : } \\
\text { • Cuci kain karet (blanket). }\end{array}$ \\
\hline 18. & $\begin{array}{lr}\text { Aparat } & \text { pemasukan } \\
\text { kertas } & \text { sering } \\
\text { berhenti } & \end{array}$ & $\begin{array}{l}\text { Keterangan : } \\
\text { - Roda taster kotor oleh tinta. } \\
\text { - Angin hembus terlalu besar. } \\
\text { - Angin hisap terlalu besar. } \\
\text { - Meja pemasukan terlalu tinggi ( Stapel tester ). } \\
\text { - Kertas lengket, kurang kocok. } \\
\text { Solusi : } \\
\text { - Kurangi angin penghembus. } \\
\text { - Kurangi angin penghisap. } \\
\text { - Atur dan sesuaikan ketinggian meja pemasukan. } \\
\text { - Kocok kertas. }\end{array}$ \\
\hline 19. & Hasil cetak lengket & $\begin{array}{l}\text { Keterangan : } \\
\bullet \quad \text { Serbuk anti set-off kurang } \\
\text { Solusi : } \\
\bullet \quad \text { Tambahkan volume anti set-off powder. }\end{array}$ \\
\hline 20 & $\begin{array}{l}\text { Keluarnya kertas } \\
\text { tidak turun ke meja } \\
\text { delivery dan mesin } \\
\text { berhenti }\end{array}$ & $\begin{array}{l}\text { Keterangan : } \\
\text { - Pelepasan pada pencapit gripper terlalu } \\
\text { kebelakang. } \\
\text { Solusi : } \\
\text { - Putar dan sesuaikan tuas stoper kertas untuk } \\
\quad \text { melepaskan kertas dari gripper }\end{array}$ \\
\hline 21. & $\begin{array}{l}\text { Jatuhnya kertas di } \\
\text { meja delivery tidak } \\
\text { rapi. }\end{array}$ & $\begin{array}{l}\text { Keterangan: } \\
\text { - Penahan dan penyangga bagian belakang tidak } \\
\text { sesuai ukuran kertas. } \\
\text { Solusi : } \\
\text { - Kencangkan puli penahan dan penyangga dan } \\
\quad \text { sesuaikan kembali jaraknya sesuai ukuran kertas. }\end{array}$ \\
\hline
\end{tabular}

Pada Tabel 3.4. merupakan contoh tabel keputusan permasalahan yang dikelompokan dari titik mesin mulai berjalan (feeder) sampai kepada akhir dari proses mencetak (delivery), sehingga diketahui alur dari proses mencetak dan bagian mana yang harus diperbaiki atau di setting ulang berdasarkan permasalahan yang terjadi. Tabel terdiri dari kode permasalahan F1 hingga F22 dan kode solusi S1 hingga S22. 
TABEL 3.4. Contoh tabel Keputusan (hanya $S 1$ hingga S9 dan F1 dari F13).

\begin{tabular}{|c|c|c|c|c|c|c|c|c|c|c|c|c|c|}
\hline KODE & F1 & F2 & F3 & F4 & F5 & F6 & F7 & F8 & F9 & F10 & F11 & F12 & F13 \\
\hline S1 & $\sqrt{ }$ & & $\sqrt{ }$ & & & & & & & & & & \\
\hline S2 & $\sqrt{ }$ & $\sqrt{ }$ & & & & & & & & & & & \\
\hline S3 & $\sqrt{ }$ & & & & & & & & & & & & \\
\hline S4 & & & $\sqrt{ }$ & & & & & & & & & & \\
\hline S5 & & & & $\sqrt{ }$ & $\sqrt{ }$ & & & & & & & & \\
\hline S6 & & & & $\sqrt{ }$ & $\sqrt{ }$ & & & & & & & & \\
\hline S7 & & & & $\sqrt{ }$ & $\sqrt{ }$ & & & & & & & & \\
\hline S8 & & & & $\sqrt{ }$ & $\sqrt{ }$ & & & & & & & & \\
\hline S9 & & & & & & $\sqrt{ }$ & & & & & & & \\
\hline
\end{tabular}

TABEL 3.5. Keterangan kode F1-F9 dan ode S1-S9 Tabel Keputusan

\begin{tabular}{|c|c|c|c|}
\hline Kode & Deskripsi & Kode & Deskripsi \\
\hline $\mathrm{F} 1$ & $\begin{array}{l}\text { Mesin tidak bisa dijalankan } \\
\text { setelah mesin dihidupkan } \\
\text { (power switch on). }\end{array}$ & S1 & Periksa dan tutup switch inch. \\
\hline $\mathrm{F} 2$ & $\begin{array}{l}\text { Lampu indikator mesin } \\
\text { berwarna merah }\end{array}$ & S2 & $\begin{array}{l}\text { Periksa dan tutup switch emergency } \\
\text { button pada mesin }\end{array}$ \\
\hline F3 & $\begin{array}{l}\text { Lampu indikator berwarna biru } \\
\text { di semua atau salah satu unit } \\
\text { berkedip. }\end{array}$ & S3 & $\begin{array}{l}\text { Periksa dan tekan tombol on pada } \\
\text { swith motor utama pada mesin di } \\
\text { bagian belakang. }\end{array}$ \\
\hline F4 & $\begin{array}{l}\text { Kertas tak terhisap oleh sucker } \\
\text { house }\end{array}$ & S4 & Periksa dan tutup kap pada mesin \\
\hline F5 & Kertas terhisap rangkap & S5 & $\begin{array}{l}\text { Atur dan sesuaikan angin } \\
\text { penghebus }\end{array}$ \\
\hline F6 & Kertas jalannya miring & S6 & Atur dan sesuaikan angin penghisap \\
\hline F7 & Cetakan lari & S7 & $\begin{array}{l}\text { Atur dan sesuaikan ketinggian meja } \\
\text { pemasukan (Stapel tester) }\end{array}$ \\
\hline F8 & Oversheet pada cetakan & S8 & Kocok kertas \\
\hline F9 & Kotor pada pinggiran kertas & S9 & Atur roda transport \\
\hline
\end{tabular}

\subsection{Perancangan Data}

Untuk mempermudah proses diagnosa troubleshooting pada mesin Heidelberg GTO V 52 program sistem pakar akan mengambil kesimpulan berdasarkan jawabanjawaban dari pemakai, pada Tabel 3.6. Data Pertanyaan (P1-P23) dan pada Tabel 3.7. solusi (S1-S19) sistem pakar terkait troubleshoot mesin Heidelberg GTO V 52. Pada tabel 3.6 dan tabel 3.7 hanya ditampilkan data pertanyaan P1 hingga P6 dan solusi S1 hingga S6. 
TABEL 3.6. Contoh data Pertanyaan Sistem Pakar Heidelberg GTO V 52

\begin{tabular}{|l|l|}
\hline No. & \multicolumn{1}{c|}{ Pertanyaan } \\
\hline P1 & Apakah mesin tidak dapat dijalankan setelah mesin dinyalakan power switch on ? \\
\hline P2 & Apakah lampu indikator berwarna merah menyala? \\
\hline P3 & $\begin{array}{l}\text { Apakah lampu indikator di salah satu unit warna atau setiap unit warna berkedip } \\
\text { berwarna biru? }\end{array}$ \\
\hline P4 & Apakah terdapat masalah di unit Feeder ? \\
\hline P5 & Apakah kertas tak terhisap oleh Sucker House ? \\
\hline P6 & Apakah kertas terhisap rangkap dan mesin berhenti ? \\
\hline
\end{tabular}

TABEL 3.7. Contoh Data Solusi Sistem Pakar Heidelberg GTO V 52

\begin{tabular}{|l|l|}
\hline No. & \multicolumn{1}{|c|}{ Solusi } \\
\hline S1 & $\begin{array}{l}\text { Pada panel mesin Heidelberg GTO V 52 switch Emergency Button masih } \\
\text { terbuka. Putar dan tekan tombol berwarna merah kearah kanan. }\end{array}$ \\
\hline S2 & $\begin{array}{l}\text { Pada mesin Heidelberg GTO V 52 terjadi switch inch yang masih terbuka. } \\
\text { Periksa setiap unit warna tombol yang masih terbuka dan periksa kap mesin yang } \\
\text { masih terbuka. }\end{array}$ \\
\hline S3 & $\begin{array}{l}\text { Pada mesin Heidelberg GTO V 52 switch motor utama belum } \\
\text { dinyalakan.Hidupkan motor utama dengan menekan tombol ON. }\end{array}$ \\
\hline S4 & $\begin{array}{l}\text { Terjadi masalah pada penghisapan kertas oleh Sucker House dan penyetelan } \\
\text { angin. Lakukan Penyetelan dengan memutar tuas penghembus angin. Periksa } \\
\text { angin penghisap, biasanya angin penghisap terlalu kecil. Periksa juga meja pada } \\
\text { feeder, biasanya meja terlalu rendah (Stape| Tester). }\end{array}$ \\
\hline S5 & $\begin{array}{l}\text { Terjadi masalah pada pengaturan angin dan penumpukan kertas terlalu rapat. } \\
\text { Penyetelan angin penghembus terlalu besar dan angin penghisap terlalu besar. } \\
\text { Periksa juga meja pemasukan (stape | tester) biasanya terlalu tinggi. Kocok } \\
\text { kembali kertas, hal ini agar kertas terisi udara. Lakukan penyetelan double kertas. }\end{array}$ \\
\hline S6 & $\begin{array}{l}\text { Pada unit Feeder kertas tidak seimbang. Periksa dan lakukan penyetelan pada } \\
\text { bagian penahan kertas. Hal ini menyebabkan kertas tertahan (terhimpit) oleh } \\
\text { penahan kertas sehingga jalannya kertas ke stopper menjadi tidak seimbang. } \\
\text { Periksa juga sucker house yang terkena area kertas agar katupnya dapat } \\
\text { menghisap. }\end{array}$ \\
\hline
\end{tabular}


TABEL 3.8. Perancangan Data Sistem Pakar

\begin{tabular}{|l|l|l|l|l|l|}
\hline KODE & Jika YA & Jika Tidak & KODE & Jika YA & Jika Tidak \\
\hline P1 & P2 & P4 & P13 & S10 & P14 \\
\hline P2 & S1 & P3 & P14 & S11 & P15 \\
\hline P3 & S2 & S3 & P15 & P16 & P17 \\
\hline P4 & P5 & P8 & P16 & S12 & S13 \\
\hline P5 & S4 & P6 & P17 & S14 & P18 \\
\hline P6 & S5 & P7 & P18 & S15 & P19 \\
\hline P7 & S6 & P8 & P19 & S16 & P8 \\
\hline P8 & P9 & P20 & P20 & P21 & P1 \\
\hline P9 & P10 & P13 & P21 & S17 & P22 \\
\hline P10 & S7 & P11 & P22 & S18 & P23 \\
\hline P11 & S8 & P12 & P23 & S19 & P1 \\
\hline P12 & S9 & S8 & & & \\
\hline
\end{tabular}

\subsection{Aturan Produksi}

Untuk menghasilkan sistem pakar diperlukan juga proses inferensi yang digunakan. Dalam penelitian ini digunakan inferensi forward chaining untuk melihat kaidah produksi yang dihasilkan dari basis pengetahuan.

Kaidah produksi dituliskan dalam bentuk jika-maka (IF-THEN), kaidah ini dapat dikatakan sebagai hubungan implikasi dari dua bagian yaitu bagian premise (jika) dan bagian konklusi (maka). Apabila premise dipenuhi maka bagian konklusi juga bernilai benar. Sebuah kaidah terdiri dari klausa-klausa yang mirip dengan kalimat subjek, kata kerja dan objek yang menyatakan suatu fakta. Dari tabel keputusan yang disajikan pada sub bab sebelumnya dapat dibuatkan juga tabel kaidah produksi. Pada tabel 10 Aturan Produksi dibawah ini dapat dilihat aturan (rule) untuk sistem pakar mesin Heidelberg.

TABEL 3.9. Aturan Produksi (rule)

\begin{tabular}{|l|l|l|l|l|l|}
\hline RULE & \multicolumn{1}{|c|}{ IF } & \multicolumn{1}{|c|}{ THEN } & \multicolumn{1}{|c|}{ RULE } & \multicolumn{1}{c|}{ IF } & \multicolumn{1}{c|}{ (HEN } \\
\hline 1 & P1 & S3 & 11 & P8, P14 & S11 \\
\hline 2 & P1,P2 & S1 & 12 & $\begin{array}{l}\text { P8, P15, } \\
\text { P16 }\end{array}$ & S12 \\
\hline 3 & P1,P3 & S2 & 13 & P8, P16 & S13 \\
\hline 4 & P4,P5 & S4 & 14 & P8, P17 & S14 \\
\hline 5 & P4,P6 & S5 & 15 & P8, P18 & S15 \\
\hline 6 & P4,P7 & S6 & 16 & P8,P19 & S16 \\
\hline 7 & P8,P9,P10 & S7 & 17 & P20, P21 & S17 \\
\hline 8 & P8,P9,P11 & S8 & 18 & P20,P22 & S18 \\
\hline 9 & P8,P9,P11,P12 & S8 & 19 & P20,P23 & S19 \\
\hline 10 & P8, P13 & S10 & & & \\
\hline
\end{tabular}




\subsubsection{Pohon Keputusan}

Pohon keputusan terdiri dari pertanyaan dan solusi. Berikut adalah gambar pohon keputusan yang terbentuk :

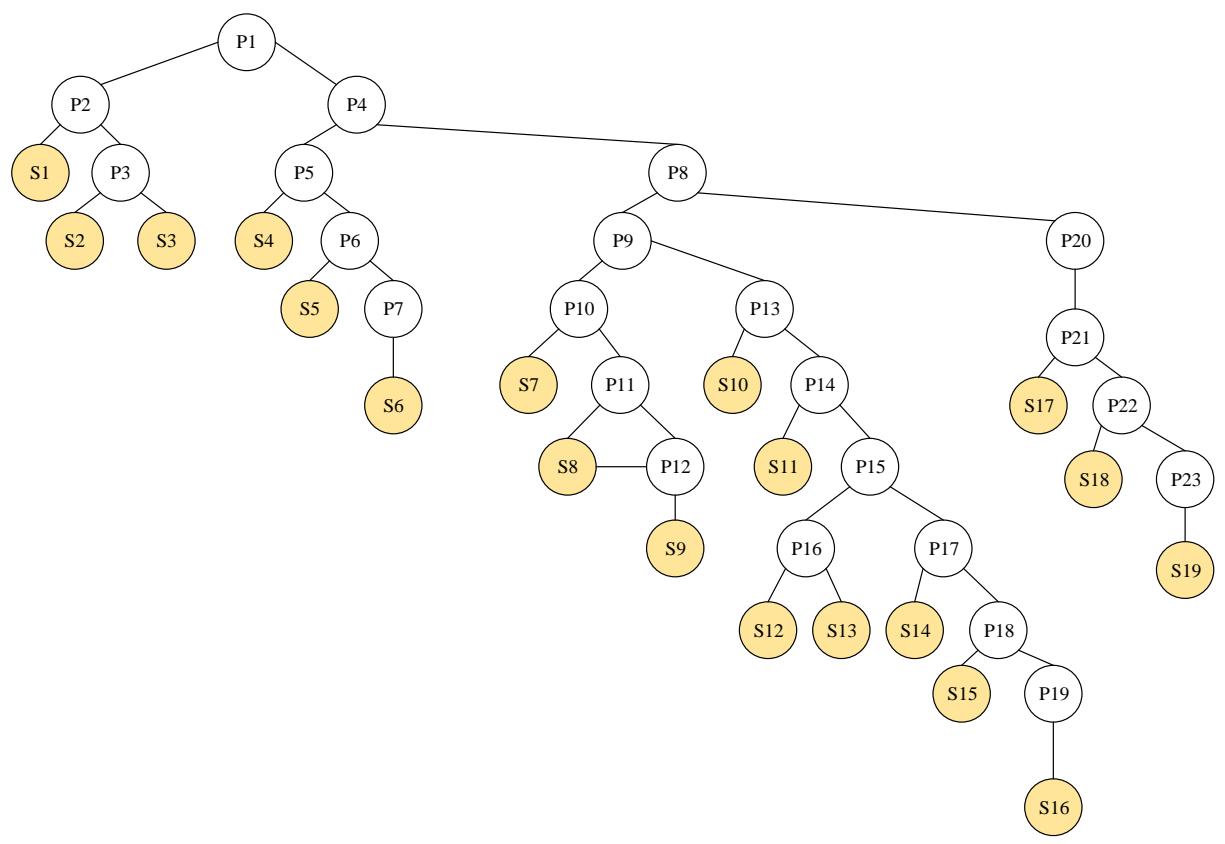

GAMBAR 3.1. Pohon Keputusan

\subsection{Perancangan Perangkat Lunak}

Perancangan perangkat lunak pada aplikasi sistem pakar yang akan di bangun ini menggunakan bahasa UML (Unified Modelling Language). UML dapat digunakan untuk memvisualisasikan, menentukan, mengkonstruksi, dan mendokumentasikan artifak-artifak suatu sistem software-intensive

\subsubsection{Use Case Diagram}

Sebuah use case diagram menceritakan sebuah cerita tentang bagaimana pengguna (memainkan salah satu dari sejumlah kemungkinan peran) berinteraksi dengan sistem. Rangkaian situasi cerita tertentu bisa berupa teks naratif, interaksi, deskripsi berbasis template, atau representasi diagram. Terlepas dari bentuknya, use case diagram menggambarkan perangkat lunak atau sistem dari sudut pandang pengguna. Gambar 3.2 memperlihatkan diagram use case dari sistem pakar. 


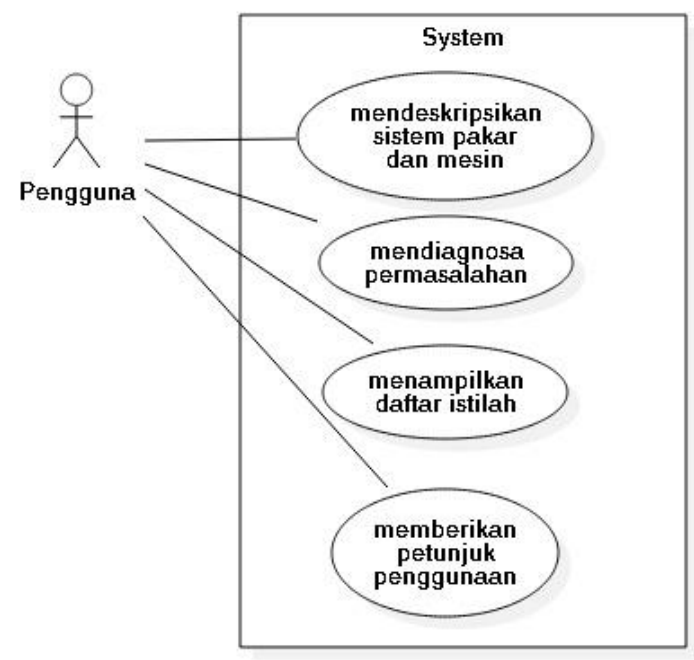

GAMBAR 3.2. Use Case Diagram Sistem Pakar

\subsubsection{Skenario Use Case}

Skenario atau flow of event use case merupakan tabel yang menggambarkan deskripsi rinci dari tiap use case. Berikut adalah skenario use case untuk setiap use case dari sistem pakar permasalahan mesin Heidelberg GTO V 52:

- Skenario use case mendeskripsikan sistem pakar dan mesin

- Skenario use case mendiagnosa permasalahan

- Skenario use case menampilkan daftar istilah

- Skenario use case memberikan petunjuk penggunaan

Tabel 3.10 memperlihat scenario use case mendeskripsikan sistem pakar.

TABEL 3.10. Skenario Use Case Mendeskripsikan Sistem Pakar Dan Mesin

\begin{tabular}{|l|l|l|}
\hline Nama use case & Mendeskripsikan sistem pakar dan mesin \\
\hline Aktor & Pengguna \\
\hline Kondisi awal & Menampilkan maksud dan tujuan dari sistem pakar \\
\hline Kondisi akhir & Mendeskripsikan tiap bagian dari mesin \\
\hline Skenario Aksi aktor & \multicolumn{1}{|c|}{ Aksi sistem } \\
\hline No & Memilih menu beranda & $\begin{array}{l}\text { Menampilkan maksud dan tujuan dari } \\
\text { sistem pakar }\end{array}$ \\
\hline 1 & $\begin{array}{l}\text { Aktor mengklik teks } \\
\text { Heidelberg GTO V 52 }\end{array}$ & $\begin{array}{l}\text { Menampilkan gambaran umum mesin } \\
\text { heidelberg GTO V 52 dan menampilkan } \\
\text { gambar mesin Heidelberg GTO V 52 4P. }\end{array}$ \\
\hline
\end{tabular}




\begin{tabular}{|l|l|l|}
\hline 3 & Aktor mengklik teks FEEDER & $\begin{array}{l}\text { Memberikan pengertian dan penjelasan } \\
\text { tentang apa itu feeder dan menampilkan } \\
\text { gambar bagian feeder mesin Heidelberg } \\
\text { GTO V 52 4P. }\end{array}$ \\
\hline 4 & $\begin{array}{l}\text { Aktor mengklik teks Unit } \\
\text { Cetak / Press Unit }\end{array}$ & $\begin{array}{l}\text { Memberikan pengertian dan penjelasan } \\
\text { tentang apa itu unit cetak dan } \\
\text { menampilkan gambar bagian unit cetak } \\
\text { pada mesin Heidelberg GTO V 52 4P. }\end{array}$ \\
\hline 5 & $\begin{array}{l}\text { Aktor mengklik teks Delivery } \\
\text { Unit }\end{array}$ & $\begin{array}{l}\text { Memberikan pengertian dan penjelasan } \\
\text { tentang apa itu delivery unit dan } \\
\text { menampilkan gambar bagian delivery unit } \\
\text { pada mesin Heidelberg GTO V 52 4P. }\end{array}$ \\
\hline
\end{tabular}

\subsubsection{Activity Diagram}

Activity diagram adalah salah satu cara untuk memodelkan event-event yang terjadi dalam suatu use case. Activity diagram dapat digunakan untuk mewakili detail pemrosesan juga merupakan teknik untuk mendeskripsikan logika prosedural. Berikut ini activity diagram dari aplikasi sistem pakar Heidelberg GTO V 52:

- Activity diagram Diagram Mendeskripsikan Sistem Pakar Dan Mesin

- Activity Diagram Diagnosa Permasalahan

- Activity Diagram Daftar Istilah

- Activity Diagram Petunjuk Penggunaan

Gambar 3.3 memperlihatkan Activity diagram Diagram Mendeskripsikan Sistem Pakar Dan Mesin 


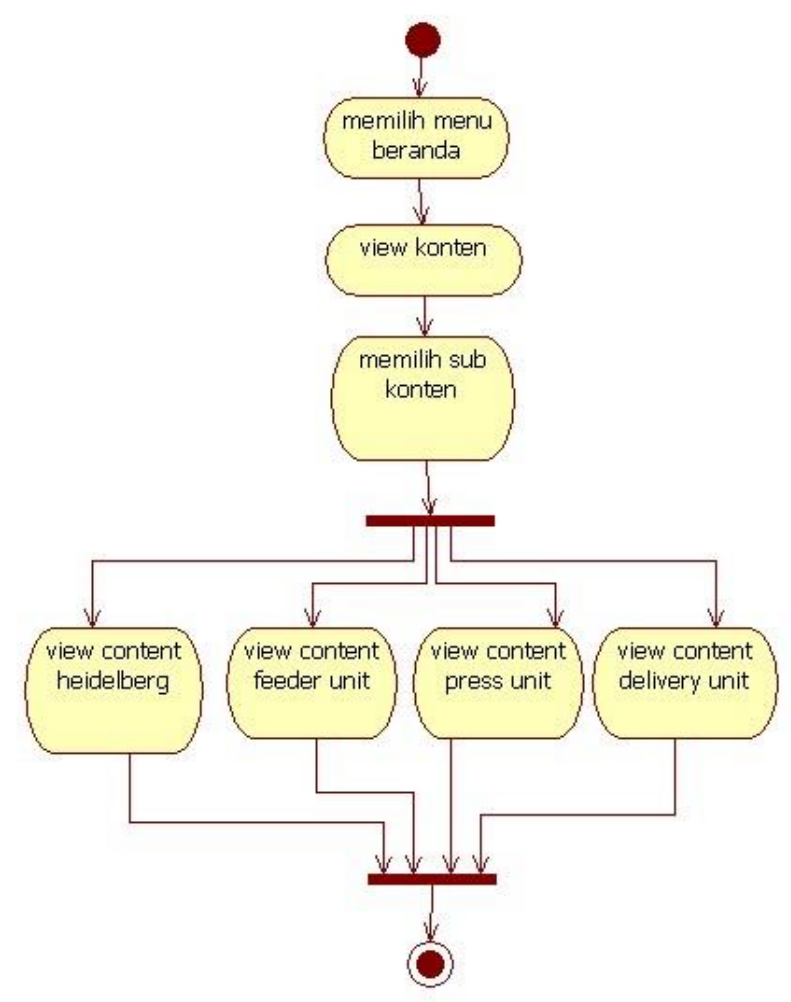

GAMBAR 3.3. Activity diagram mendeskripsikan sistem pakar dan mesin

\subsubsection{Sequence Diagram}

Sequence diagram biasa digunakan untuk menggambarkan skenario atau rangkaian langkah-langkah yang dilakukan sebagai respon dari sebuah event untuk menghasilkan output tertentu.

Diagram sequence memperlihatkan tahap demi tahap apa yang seharusnya terjadi untuk menghasilkan sesuatu didalam use case. Menggambarkan iterasi antara seujmlah objek dalam urutan waktu. Sequence diagram yang dirancang untuk sistim pakar ini adalah sebagai berikut:

- Sequence Diagram Beranda

- Sequence Diagram Diagnosa

- Sequence Diagram Daftar Istilah

- Sequence diagram pentunjuk penggunaan 
Gambar 3.4 memperlihatkan Sequence Diagram Beranda

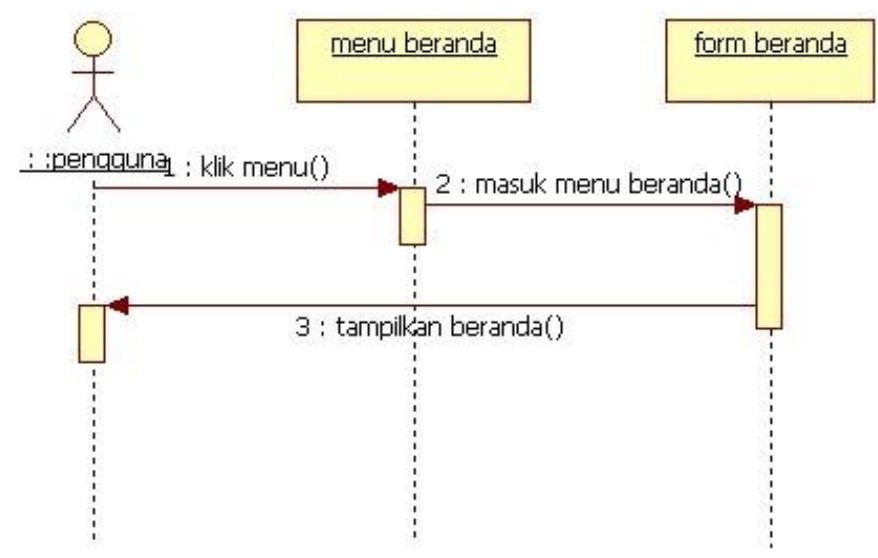

GAMBAR 3.4. Sequence Diagram Beranda

\subsubsection{Deployment Diagram}

Deployment diagram menggambarkan detail bagaimana komponen dalam infrastruktur sistem, di mana komponen akan terletak, bagaimana kemampuan jaringan pada lokasi tersebut, spesifikasi server, dan hal-hal lain yang bersifat fisikal

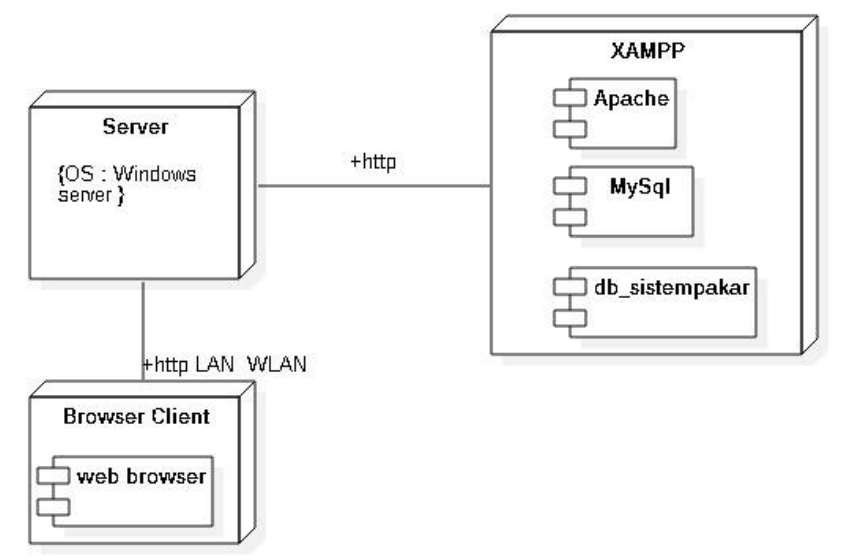

GAMBAR 3.5. Deployment Diagram Sistem Pakar

\subsection{Perancangan Basis Data}

Tabel basis data sistim pakar yang dirancang terdiri dari tabel diagnose dan tabel istilah.

Nama tabel : tb_diagnosa

Deskripsi : Menyimpan pertanyaan dan jawaban

Primary key : id_diagnosa 
TABEL 3.11. Tabel Diagnosa

\begin{tabular}{|l|l|l|l|}
\hline Nama Field & Tipe data & Length & \multicolumn{1}{c|}{ Description } \\
\hline id_diagnosa & INT & 11 & Primary key \\
\hline qanda & VARCHAR & 6000 & String pertanyaan dan jawaban \\
\hline if_true & INT & 11 & Kode id jika benar (jawaban ya) \\
\hline if_false & INT & 11 & Kode id jka salah (jawaban tidak) \\
\hline start & CHAR & 1 & $\begin{array}{l}\text { Awal pertanyaan dan pertanyaan } \\
\text { selanjutnya }\end{array}$ \\
\hline end & CHAR & 1 & Akhir pertanyaan \\
\hline gambar1 & VARCHAR & 255 & Deskkripsi gambar untuk jawaban \\
\hline gambar2 & VARCHAR & 255 & Deskkripsi gambar untuk jawaban \\
\hline gambar3 & VARCHAR & 255 & Deskkripsi gambar untuk jawaban \\
\hline desk & VARCHAR & 255 & Deskkripsi gambar untuk pertanyaan \\
\hline
\end{tabular}

Nama tabel : tb_istilah

Deskripsi : menyimpan pertanyaan dan jawaban

Primary key : id_istilah

TABEL 3.12. Tabel Istilah

\begin{tabular}{|l|l|l|l|}
\hline \multicolumn{1}{|c|}{ Nama Field } & Tipe data & Length & \multicolumn{1}{c|}{ Description } \\
\hline Id_istilah & Int & 11 & Primary key \\
\hline Istilah & Varchar & 100 & Nama istilah \\
\hline Keterangan & text & & Keterangan istilah \\
\hline
\end{tabular}

\subsection{Perancangan Antar Muka}

Perancangan antar muka merupakan rancangan tampilan yang akan digunakan sebagai perantara user dengan perangkat lunak yang akan dikembangkan. Layout antarmuka atau halaman berupa menu dan sub-menu dari aplikasi sistem pakar ini teridiri dari: Antarmuka Beranda, Antarmuka fade effect, Antarmuka Diagnosa, Antarmuka Solusi, Antarmuka Daftar Istilah, Antarmuka Petunjuk Penggunaan. Gambar berikut memperlihatkan gambar rancangan antar muka untuk beranda. 


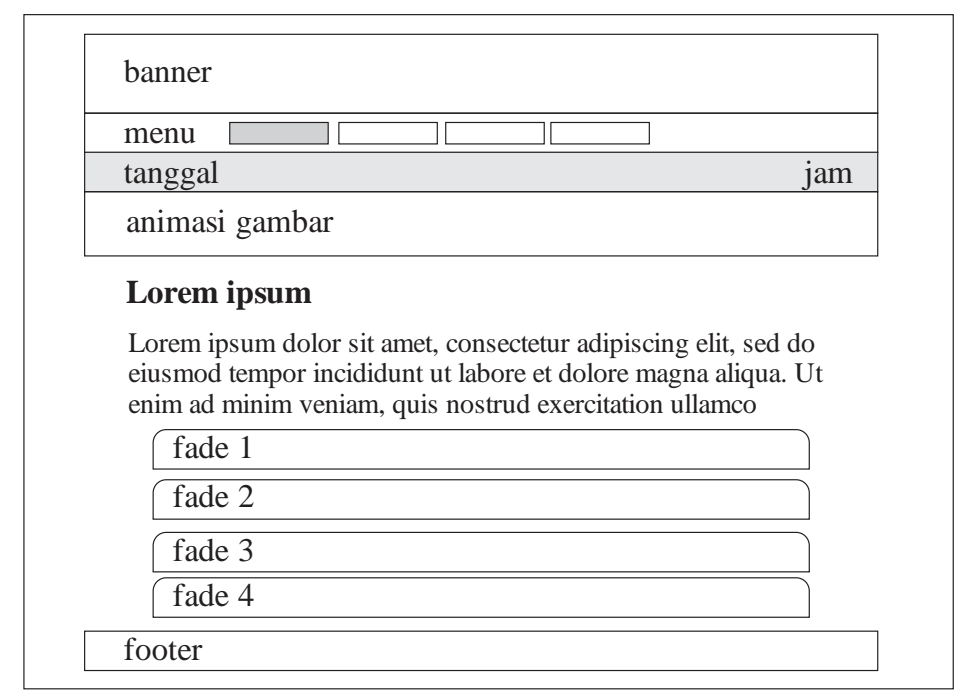

Gambar 3.6. Rancangan Antarmuka Beranda

\subsection{Implementasi Sistem}

Rancangan yang telah dilkakuan kemudian diimplementasikan dalamtampilan menu dan sub-menu yang terdidri dari: Tampilan Menu Beranda, Halaman Beranda Heidelbeg GTO V 52, Halaman Beranda Feeder dan Cetak, Halaman Diagnosa, Halaman Solusi, Halaman Daftar Istilah, Halaman Pencarian Istilah, Halaman Petunjuk Penggunaan, Halaman Penggunaan Menu Diagnosa, Halaman Pengoperasian Mesin, dan Halaman Responsive. Gambar berikut merupakan contoh implementasi Halaman Beranda.

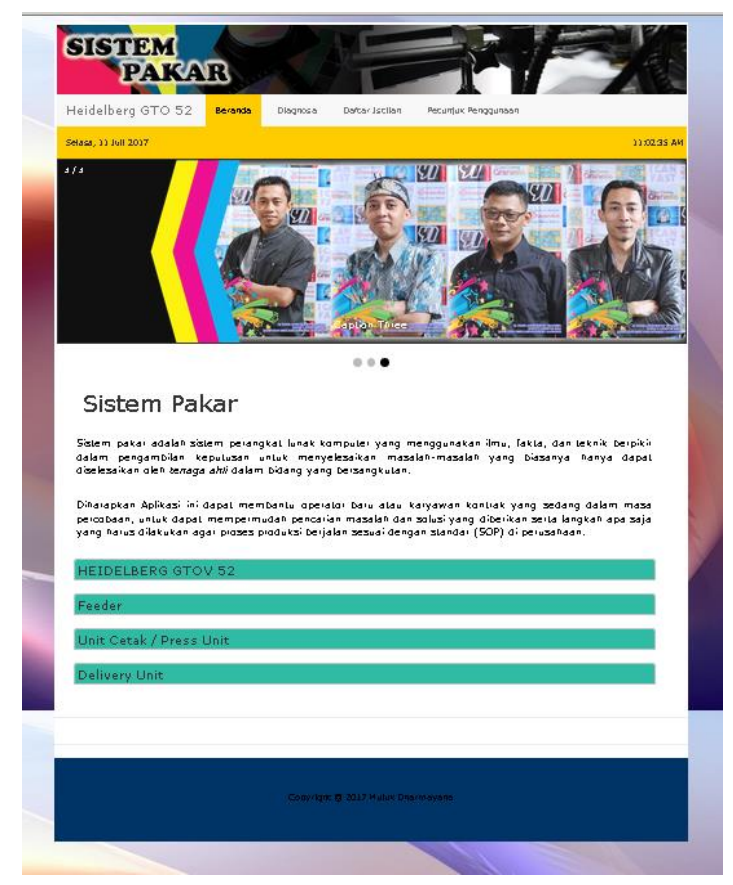

GAMBAR 3.7. Implementasi Halaman Beranda 


\subsection{Pengujian Sistem}

Hasil pengujian dilakukan dengan menggunakan metode Black Box Testing. Pengujian ini berusaha menemukan kesalahan dalam kategori fungsi-fungsi yang tidak benar atau hilang, kesalahan interface, kesalahan dalam struktur data atau akses basis data eksternal, kesalahan kinerja, dan inisialisasi dan kesalahan terminal. Dengan menggunakan metode pengujian black box, perekayasa sistem dapat menemukan kesalahan dalam kategori sebagai berikut :

1. Fungsi tidak benar atau hilang

2. Kesalahan antar muka

3. Kesalahan pada struktur data (pengaksesan database)

4. Kesalahan inisialisasi dan akhir program

5. Kesalahan kinerja

TABEL 3.13. Pengujian Sistem

\begin{tabular}{|c|c|c|c|c|}
\hline No. & Kelas Uji & Daftar Pengujian & Skenario Uji & Hasil \\
\hline \multirow[t]{4}{*}{1} & \multirow{4}{*}{$\begin{array}{l}\text { Membuka } \\
\text { localhost } \\
\text { /127.0.0.1/ } \\
\text { heidelberg }\end{array}$} & $\begin{array}{l}\text { Dengan menggunakan } \\
\text { browser : }\end{array}$ & $\begin{array}{l}\text { Membuka file } \\
\text { index.php }\end{array}$ & \\
\hline & & $\begin{array}{lll}\text { Mozila } & \text { FireFox } 54.0 .1 \\
\text { (32-bit) } & & \end{array}$ & & Sesuai \\
\hline & & Internet explorer 8 & & Sesuai \\
\hline & & Chrome & & Sesuai \\
\hline \multirow[t]{8}{*}{2} & \multirow[t]{2}{*}{ Klik menu } & $\begin{array}{l}\text { Klik menu beranda, } \\
\text { dengan browser: }\end{array}$ & \multirow[t]{2}{*}{$\begin{array}{l}\text { Menampilkan } \\
\text { halaman beranda }\end{array}$} & Sesuai \\
\hline & & $\begin{array}{l}\text { Mozila } \\
\text { (32-bit) }\end{array}$ & & Sesuai \\
\hline & & Internet explorer 8 & \multirow[t]{2}{*}{$\begin{array}{l}\text { Menampilkan } \\
\text { halaman beranda }\end{array}$} & $\begin{array}{l}\text { Slide show } \\
\text { tidak tampil }\end{array}$ \\
\hline & & $\begin{array}{ll}\text { Chrome } & \text { Versi } \\
59.0 .3071 .115 & \end{array}$ & & Sesuai \\
\hline & & $\begin{array}{l}\text { Klik menu fade effect, } \\
\text { dengan browser: }\end{array}$ & $\begin{array}{l}\text { Menampilkan } \\
\text { halaman bagian- } \\
\text { bagian mesin }\end{array}$ & \\
\hline & & $\begin{array}{l}\text { Mozila } \\
\text { (32-bit) }\end{array}$ & & Sesuai \\
\hline & & Internet explorer 8 & & Tidak tampil \\
\hline & & $\begin{array}{ll}\text { Chrome } & \text { Versi } \\
59.0 .3071 .115 & \\
\end{array}$ & & Sesuai \\
\hline & & $\begin{array}{l}\text { Klik menu diagnosa, } \\
\text { dengan browser: }\end{array}$ & $\begin{array}{l}\text { Menampilkan } \\
\text { halaman diagnosa }\end{array}$ & \\
\hline & & $\begin{array}{lll}\text { Mozila } & \text { FireFox } & 54.0 .1 \\
\text { (32-bit) } & & \end{array}$ & & Sesuai \\
\hline
\end{tabular}




\begin{tabular}{|c|c|c|c|c|}
\hline & & Internet explorer 8 & & \multirow{2}{*}{$\begin{array}{l}\text { Sesuai } \\
\text { Sesuai }\end{array}$} \\
\hline & & $\begin{array}{ll}\text { Chrome } & \text { Versi } \\
59.0 .3071 .115 & \\
\end{array}$ & & \\
\hline & & $\begin{array}{l}\text { Klik menu daftar istilah, } \\
\text { dengan browser : }\end{array}$ & $\begin{array}{l}\text { Menampilkan } \\
\text { halaman daftar } \\
\text { istilah }\end{array}$ & \\
\hline & & $\begin{array}{lll}\begin{array}{l}\text { Mozila } \\
\text { (32-bit) }\end{array} & \text { FireFox } & 54.0 .1 \\
\end{array}$ & & Sesuai \\
\hline & & Internet explorer 8 & & Sesuai \\
\hline & & $\begin{array}{ll}\text { Chrome } & \text { Versi } \\
59.0 .3071 .115 & \\
\end{array}$ & & Sesuai \\
\hline \multirow[t]{4}{*}{3} & \multirow[t]{4}{*}{ Input kata } & \multirow[t]{4}{*}{$\begin{array}{l}\text { Melakukan pencarian } \\
\text { data istilah }\end{array}$} & $\begin{array}{l}\text { Bila satu huruf / } \\
\text { angka }\end{array}$ & Sesuai \\
\hline & & & Bila sebagian kata & Sesuai \\
\hline & & & Bila satu kata & Sesuai \\
\hline & & & $\begin{array}{l}\text { Bila tidak terdapat } \\
\text { dalam database }\end{array}$ & $\begin{array}{l}\text { Menampilkan } \\
\text { pemberitahuan }\end{array}$ \\
\hline 4 & Klik menu & $\begin{array}{l}\text { Klik menu petunjuk } \\
\text { penggunaan }\end{array}$ & $\begin{array}{l}\text { Menampilkan } \\
\text { halaman petunjuk } \\
\text { penggunaan }\end{array}$ & sesuai \\
\hline 5 & $\begin{array}{l}\text { Resolusi } \\
\text { layar }\end{array}$ & Responsive halaman & $\begin{array}{l}\text { Mengubah menu } \\
\text { menjadi halaman } \\
\text { responsive }\end{array}$ & Sesuai \\
\hline \multirow[t]{4}{*}{6} & \multirow[t]{4}{*}{$\begin{array}{l}\text { Hostpot } \\
\text { mode }\end{array}$} & $\begin{array}{lr}\text { Membuka } & \text { aplikasi } \\
\text { dengan } & \text { smartphone, } \\
\text { dengan } & \text { menggunakan } \\
\text { browser : } & \\
\end{array}$ & \multirow[t]{4}{*}{$\begin{array}{l}\text { Mengubah menu } \\
\text { menjadi halaman } \\
\text { mobile version }\end{array}$} & \\
\hline & & $\begin{array}{lll}\begin{array}{l}\text { Mozila } \\
\text { (32-bit) }\end{array} & \text { FireFox } 54.0 .1 \\
\end{array}$ & & Sesuai \\
\hline & & Opera & & Sesuai \\
\hline & & $\begin{array}{ll}\text { Chrome } & \text { Versi } \\
59.0 .3071 .115 & \end{array}$ & & Sesuai \\
\hline
\end{tabular}

\section{KESIMPULAN}

Berdasarkan hasil penelitian dan pembahasan mengenai aplikasi sistem pakar maka dapat ditarik kesimpulan sebagai berikut :

1. Sistem pakar yang telah dirancang sudah diuji dengan metode Black Box. Hasil pengujian menunjukkan bahwa tidak ditemukan kesalahan dalam kategori fungsi-fungsi, interface, kesalahan dalam struktur data atau akses basis data eksternal, kesalahan kinerja, dan inisialisasi dan kesalahan terminal

2. Dengan dibangunnya aplikasi sistem pakar bagi karyawan baru ataupun karyawan kontrak dapat menjadi bahan untuk membantu mengatasi permasalahan. 
3. Aplikasi sistem pakar dapat menambah pengetahuan tentang teknik cetak grafika khususnya ketika terjadi troubleshooting.

4. Untuk bidang keahlian yang jarang ditemui contohnya dalam kasus operator mesin cetak, belum banyak sekolah formal yang mempelajari tentang teknik mesin cetak offset. Sehingga dengan menerapkan sistim pakar sangat membantu perusahaan dalam mengatasi kelangkaan tenaga kerja ahli.

\section{DAFTAR PUSTAKA}

Andi Kristanto. 2010. Kupas Tuntas PHP \& MYSQL. Jam Menguasai PHP dan MYSQL dengan Mudah \& Cepat.Klaten : Cable Book.

Antonius Bowo Wasono, "Teknik Grafika Dan Industri Grafika”, Jilid 3, Departemen Pendidikan Nasional, 2008.

Arhami, M. 2005. Konsep Dasar Sistem Pakar. Yogyakarta: Andi.

Endro Santoso HS, “Teknik Cetak Tinggi dan Cetak Dalam”, Daftar Istilah Lampiran B, [b1-b30], Direktorat Jenderal Pendidikan Menengah Kementerian Pendidikan Dan Kebudayaan, 2013.

Endro Santoso HS, “Teknik Cetak Tinggi dan Cetak Dalam”, Direktorat Jenderal Pendidikan Menengah Kementerian Pendidikan Dan Kebudayaan, 2013.

Kusrini. 2008. Aplikasi Sistem Pakar. Yogyakarta: Andi.

Pusat Grafika Indonesia, "Pengajaran Terprogramkan Cetak Offset”, jilid 1 s/d 6". Jakarta, 1978.

Roger S. Pressman, Ph.D., "Software Engineering, A Practitioner's Approach", Edition $7^{\text {th }}$, Higher Education, 2010. [Online]. Tersedia di: https://ia800203.us.archive.org/24/items/SoftwareEngineering7thEDByRogerS.Pr essman/Software-

Engineering\%207th\%20ED\%20by\%20Roger\%20S.\%20Pressman.pdf (20 Juni 2017)

Sri Kusumadewi, “Artificial Intelligence (Teknik dan Aplikasinya)”, Graha Ilmu, 2003. 